\title{
Impressions from EASD 2021
}

\section{Dr Caroline Day reports on the European Association for the Study of Diabetes 57th Annual Meeting, aka Virtual EASD 2021}

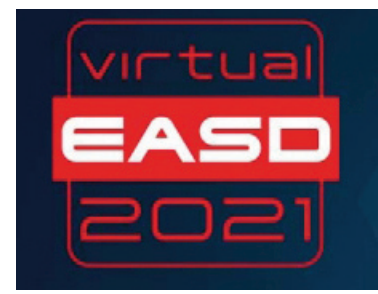

\begin{abstract}
Introduction
The 57th Annual EASD meeting was due to be held in Stockholm but, courtesy of COVID-19, it was again hosted exclusively in cyberspace. Nevertheless, every cloud has a silver lining: no promotional banners, signage and exhibition stands to be constructed, demolished and consigned to landfill; delegates and conference professionals are spared the rigours of international travel and carbon footprint concerns, whilst the reduced costs (time, energy, money) of conference attendance facilitates diversity and inclusivity, ideally improving intellectual intercourse. ${ }^{1}$ This year virtual attendance $(n=14,373)$ was similar to actual attendance in $2019(n=14,562)$. Participants were from 136 countries, with large contingencies from beyond Europe eg, Mexico $(n=490)$, USA ( $n=430)$, Egypt $(n=368)$, Columbia $(n=333)$ - and UK attendance ranked third ( $n=657)$ behind Germany $(n=1,081)$ and Brazil $(n=770)$.
\end{abstract}

\begin{abstract}
s and access
Accessing an online flipbook from the Virtual Meeting or downloading a 306-page pdf of the final programme via your My-EASD. account or https://upload.easd.org/download/EASD2021/Flipbook/mobile/index.html allows easy navigation of the event - the programme at a glance starts on page 20, symposia are listed from page 213 and industry sessions commence on page 228 . The meeting day is highly civilised, commencing at 10am and ending with a daily 'wrap up' session, the latest of which commenced at $5.30 \mathrm{pm}$. The abstracts $(n=702)$ are published in Diabetologia and can be accessed online (downloadable pdf). ${ }^{2}$ At the meeting Abstracts 1-260 were presented in 47 oral sessions (OP) and, in lieu of posters, Abstracts 261-702 were presented during six (A-F) short oral discussion events (SO). Abstracts and webcasts can be viewed free of charge on the EASD virtual meeting site. ${ }^{3}$
\end{abstract}

\section{Highlights}

As usual it was worth dropping in on the prize lectures (Table 1). Trials which had devoted sessions at EASD are listed in Table 2. The EASD e-learning sessions proved popular with $>260,000$ on-demand views during the meeting. Naturally, COVID-19 was an area of interest at this meeting, warranting two dedicated
Table 1 Award lectures at EASD 2021

\begin{tabular}{|c|c|c|}
\hline Prize & Lecturer & Title (day and time of presentation) \\
\hline $\begin{array}{l}\text { 53rd Claude Bernard } \\
\text { Lecture }\end{array}$ & $\begin{array}{l}\text { Juleen R Zierath } \\
\text { Sweden/Denmark }\end{array}$ & $\begin{array}{l}\text { Sending the right signals - how exercise keeps the } \\
\text { rhythm in metabolism } \\
\text { Tuesday, 10.30am }\end{array}$ \\
\hline $\begin{array}{l}\text { 36th Camillo Golgi } \\
\text { Lecture }\end{array}$ & $\begin{array}{l}\text { Hiddo J L Heerspink } \\
\text { Netherlands }\end{array}$ & $\begin{array}{l}\text { Personalising the treatment for patients with } \\
\text { type } 2 \text { diabetes: the mean is meaningless } \\
\text { Tuesday, } 3 \text { pm }\end{array}$ \\
\hline $\begin{array}{l}\text { 15th Albert Renold } \\
\text { Lecture }\end{array}$ & $\begin{array}{l}\text { Pedro L Herrera } \\
\text { Switzerland }\end{array}$ & $\begin{array}{l}\text { Metabolic and functional specialisation of the } \\
\text { pancreatic beta cell } \\
\text { Tuesday, 3pm }\end{array}$ \\
\hline $\begin{array}{l}\text { 7th EASD-Novo Nordisk } \\
\text { Foundation Diabetes } \\
\text { Prize for Excellence }\end{array}$ & $\begin{array}{l}\text { John A Todd } \\
\text { UK }\end{array}$ & $\begin{array}{l}\text { From HLA-DQ position } 57 \text { and back again } \\
\text { Wednesday, } 3.15 \mathrm{pm}\end{array}$ \\
\hline 56th Minkowski Lecture & $\begin{array}{l}\text { Amelie Bonnefond } \\
\text { France }\end{array}$ & $\begin{array}{l}\text { Hunt for variants and pretty little things in the } \\
\text { genetics of diabetes } \\
\text { Thursday, } 3.15 \mathrm{pm}\end{array}$ \\
\hline
\end{tabular}

sessions (Wednesday, 4.30pm and Friday, $10 \mathrm{am})$ as well as several individual presentations (eg, Abstracts 30, 307-309, 343, 578, 690-695.

The centenary of the discovery of insulin by the Toronto team was celebrated at this year's meeting (Wednesday, 4.30pm) and a special issue of Diabetologia was available to download. ${ }^{4}$ There were EASD e-learning Insulin@100 sessions (Wednesday, 10am and 3.15pm; Thursday, 11.45am and 3.15pm; Friday, $12.30 \mathrm{pm}$ ) as well as a session to launch the 2021 ADA-EASD consensus report on the management of type 1 diabetes. ${ }^{5}$

There was a lot of interest in incretinbased therapies, with two dedicated sessions at $10 \mathrm{am}$ and one at $4.15 \mathrm{pm}$ on Thursday 30th, plus an Insulin@100 session (11.45am) and dedicated oral presentation sessions (eg, OP 04 Abstracts 19-24; OP 30 Abstracts 175180; OP 32 Abstracts 187-192) and short discussion events (eg, SO 28 Abstracts 452-459 (GLP-1 RA and weight loss); SO 30 Abstracts 470-476 (dual agonists); and SO 31 Abstracts 477-486 (focusing on semaglutide), plus presentations in non-incretin-related sections (eg, Abstracts 426, 446-449, 427, 460, 467, 500).

The sodium glucose co-transporter-2 inhibitors (SGLT2i) dapagliflozin and empagliflozin had sessions providing updates from the DAPA-CKD and EMPEROR Preserved studies (Thursday, 3.15pm and $4.15 \mathrm{pm}$, respec- tively) and there was a session considering use of this drug class in patients at cardiorenal risk (Tuesday 26, 5.40pm). There were also SGLT2i dedicated oral presentation sessions (eg, OP 9 Abstracts 49-54; OP 34 Abstracts 199-204) and short discussion events (eg, SO $26 \mathrm{Ab}$ stracts 437-443; SO 32 Abstracts 487-493) plus presentations in non-SGLT2i sections (eg, Abstracts 444, 445, 496, 497).

In DAPA-CKD, in addition to chronic kidney disease (CKD), 11\% ( $n=468)$ of subjects had heart failure (HF) at baseline. Treatment with dapagliflozin improved all outcomes regardless of HF status, and improvements were greater in patients with HF. Similarly, in patients with and without peripheral artery disease (PAD) and in patients with and without atrial fibrillation (AF), dapagliflozin treatment improved outcomes and the dapagliflozinassociated risk reductions were greater in patients with PAD or AF. ${ }^{6}$ Dapagliflozin slowed the long-term eGFR decline in patients with CKD \pm type 2 diabetes, with benefits being greater in patients with type 2 diabetes, higher $\mathrm{HbA}_{1 \mathrm{c}}$ and higher urinary albumin: creatinine ratio. ${ }^{7}$ Albuminuria was reduced in patients taking dapagliflozin, with a larger relative reduction being observed in patients with type 2 diabetes. ${ }^{8}$ A combined analysis of data from DAPA-HF and DAPA-CKD (both trials included patients with and without type 2 diabetes at baseline: $55 \%$ and $33 \%$, respectively) showed that use of dapagliflozin 
Table 2 Trials with devoted sessions

\section{Trial}

DAPA-CKD

A study to evaluate the effect of DAPAgliflozin on renal outcomes and cardiovascular mortality in patients with Chronic Kidney Disease

\section{EMPEROR-Preserved}

EMPagliflozin outcomE tRial in patients with chrOnic heart failuRe with

Preserved ejection fraction

\section{GRADE}

Glycaemia Reduction Approaches in Diabetes: a comparative

Effectiveness study

\section{HARPdoc RCT}

Hypoglycaemia Awareness Restoration Programme Randomised

Controlled Trial

\section{TriMASTER}

A 3-way cross-over trial of precision medicine strategy of $2 \mathrm{nd} / 3 \mathrm{rd}$ line therapy in type 2 diabetes

\section{Presenters}

S E Inzucchi, D C Wheeler, J J McMurray

J Butler, S D Anker, G Filipatos, M Packer, A Norhammar

D M Nathan, J B Buse, M A Tiktin, $N$ Younes, D R Matthews

H Rogers, N De Zoysa, S A Amiel, R A Aljan

A T Hattersley, E R Pearson, C Angwin, B Shields, C Kirstorp reduced new-onset diabetes by $33 \%$.

Data from a pooled analysis of the EMPEROR Preserved study and EMPEROR Reduced study (trials in patients with heart failure with preserved and reduced ejection fraction (HFpEF and HFrEF), respectively, with and without type 2 diabetes) showed that the effects of empagliflozin to reduce HF outcomes in both studies were highly concordant. $A \geq 30 \%$ reduction in hospitalisations for HF (ejection fractions $<25 \%-<65 \%$ ) was observed, but ejection fraction influenced the effect of empagliflozin on major renal outcomes - decreasing the risk in patients with HFrEF.

The TriMASTER trial is a three-way crossover study in which patients were randomised to an oral agent (canagliflozin, pioglitazone, sitagliptin) as add-on to metformin, with the add-on agent being switched every 16 weeks without a washout period. Overall, $\mathrm{HbA}_{1 \mathrm{c}}$ lowering was similar with all treatments. In patients with $\mathrm{BMI}<30$ $\mathrm{kg} / \mathrm{m}^{2}$, sitagliptin was more effective at improving $\mathrm{HbA}_{1 \mathrm{c}}$ than pioglitazone, but the opposite was observed in patients with $\mathrm{BMI}>30$ $\mathrm{kg} / \mathrm{m}^{2}$. Sitagliptin reduced $\mathrm{HbA}_{1 \mathrm{c}}$ more effectively in patients with eGFR 60-90, whereas canaglifolozin was the more effective agent in patients with eGFR >90. Patient add-on drug preferences were canagliflozin 39\%, sitagliptin $35 \%$ and pioglitazone $26 \%$. When these responses were checked at an individual level, it became evident that the preferred drug was the agent which resulted in fewest side effects and provided the greatest improvement in $\mathrm{HbA}_{1 \mathrm{c}}$.

The session on INNODIA (Thursday, $4.15 \mathrm{pm}$ ) is not available as an EASD webcast. INNODIA (www.innodia.eu) is a consortium which collects blood samples from people throughout Europe with newly diagnosed type 1 diabetes and their first-degree relatives to facilitate research to predict risk of diabetes development and mechanisms to reduce risk and cure diabetes. INNODIA's current intervention studies are called VER-A-T1D, MELDATG, CFZ533 and IMPACT.

The GRADE study (Friday, $1.45 \mathrm{pm}$ ) discussed the results of the trial to date, which appeared to be as elucidated at the 2021 American Diabetes Association annual meeting. The webcast commentary provides an excellent synopsis. The HARPdoc RCT (Friday, 1.45pm) compared two educational approaches to obviate problematic hypoglycaemia in adults with type 1 diabetes for $\geq 4$ years: HARPdoc and blood glucose awareness training (BGAT). At 12 and 24 months the incidence of severe hypoglycaemia was the same on each programme, but the HARPdoc programme was more effective than the BGAT programme at reducing diabetes distress, anxiety and depression. Webcasts of the session on finerenone (Friday, 11.15am) are not available, but use of selective nonsteroidal mineralocorticoid receptor antagonist has improved cardiorenal outcomes in patients with type 2 diabetes and CKD with elevated albuminuria. Compared with placebo, finerenone treatment improved cardiovascular outcomes - notably hospitalisation for HF - in type 2 diabetes patients with CKD stages 2-4 and moderate albuminuria, or CKD stage 1 or 2 with elevated albuminuria. ${ }^{9}$

\section{The future}

The 58th EASD is scheduled to be held in Sweden on 19-23 September 2022. Hopefully, next year we will be able to choose between virtual or actual attendance

\section{References}

1. Leochico CFD, DiGiusto ML, Mitre R. Impact of scientific conferences on climate change and how to make them eco-friendly and inclusive: a scoping review. J Clim Change Health 2021;4:10042. https://doi.org/10.1016/j.joclim.2021.100042

2. Abstracts. 57th EASD Annual Meeting of the European Association for the Study of Diabetes 27 September-1 October 2021. Diabetologia 2021;64(Suppl 1):S1-\$380. https://doi.org/10.1007/s00125-0201-05519-y

3. EASD Virtual meeting, 2021. https://www.easd.org/virtualmeeting/home.ht ml\#! events/16/programs/2021-09-27

4. Celebrating 100 years of Insulin. Diabetologia. Special Issue, May 2021,64:pp127. https://doi.org/10.1007/s00125-021-05417-3

5. Holt RIG, DeVries JH, Hess-Fischl A, et al. The management of type 1 diabetes in adults. A Consensus Report by the American Diabetes Association (ADA) and the European Association for the Study of Diabetes (EASD). Diabetes Care 2021;44:2589-625. https://doi.org/10.2337/dci21-0043 and Diabetologia 2021;64:2609-52. https://doi.org/10.1007/s00125-021-05568-3

6. MCMurray JJV, Wheeler DC, Stefansson BV, et al, on behalf of the DAPA-CKD Trial Committees and Investigators. Effects of dapagliflozin in patients with kidney disease, with and without heart failure. JACC Heart Failure 2021;9:807-20. https://doi.org/10.1016/j.jchf.2021.06.017

7. Heerspink HJL, Jongs N, Chertow GM, et al, for the DAPA-CKD Trial Committees and Investigators. Effect of dapagliflozin on the rate of decline in kidney function in patients with chronic kidney disease with and without type 2 diabetes: a prespecified analysis from the DAPA-CKD trial. Lancet Diabetes Endocrinol 2021;9:743-54. https://doi.org/10.1016/S22138587(21)00242-4

8. Jongs N, Greene T, Chertow GM, et al, for the DAPA-CKD Trial Committees and Investigators. Effect of dapagliflozin on the rate of decline in kidney function in patients with chronic kidney disease with and without type 2 diabetes: a prespecified analysis from the DAPA-CKD trial. Lancet Diabetes Endocrinol 2021;9:755-66. https://doi.org/10.1016/S22138587(21)00243-6

9. Pitt B, Filipatos G, Agarwal R, et al, and FIGARO-DKD Investigators, Cardiovascular events with finerenone in kidney disease and type 2 diabetes. N Engl J Med 2021. https://doi.org/10.1056/NEJMoa2110956

Correspondence: Dr Caroline Day, Visiting Fellow, Diabetes Group, Aston University, Birmingham B4 7ET, UK E-mail: cday@mededuk.com

http://dx.doi.org/10.15277/bjd.2021.332 Br J Diabetes 2021;21:291-292 